\title{
Why should we save water? Education on water conservation for villagers of Tianyar, Bali
}

\author{
Desi Adhariani* \\ *Department of Accounting, Faculty of Economics and Business, Universitas Indonesia
}

\begin{abstract}
This study examined the household water conservation program for villagers of Tianyar, Bali who experienced water scarcity in arid regions. The educational program consists of several activities followed by three focus group discussions to develop community awareness on the methods to save water for household consumption. The results indicate the rising awareness among villagers on the importance of water conservation and methods to save water while maintaining the healthy living standard.
\end{abstract}

\section{Introduction}

One of the Sustainable Development Goals is to ensure availability and sustainable management of water and sanitation. It is targeted that by 2030, there is a substantial increase in water-use efficiency across all sectors and sustainable withdrawals and supply of freshwater to address water scarcity. In line with this goal, there is no doubt on the promotion of water conservation practices especially in arid climates and regions to help solve the water scarcity problem. The management of water resources is needed to face the challenges of the population increases, consumer demand, and increasing costs (including environmental costs) of developing new water supplies [1].

This study reports the water conservation program conducted in an arid region in Tianyar Village in Bali, Indonesia. Understanding how such program or intervention can lead to environmentally friendly behaviors in general, and water conservation behaviors in particular, will enable water saving activities to be more successful and any development assistance to be used more wisely [2].

The program was conducted from April-September 2018 and consists of several water saving activities performed by 50 villagers as the participants; followed by three focus group discussions (FGDs). The FGDs were designed as the sharing platform among participants as well as the knowledge dissemination from mentor to participants. This study is expected to contribute to the literature of water conservation program for villagers with a relative low level of education. The practical contribution lies in the design of the program which is expected to inform similar studies or contribute to the policies to be implemented by the government or other policymakers.

${ }^{*}$ Corresponding author: desi.adhariani@ui.ac.id 


\section{Literature review}

Theoretically, a sustainable way of life requires a propensity for the future [3]. A person who has concern over the environment will anticipate the consequences of own behavior and exercise long-term thinking; which will lead to sustainable behaviors. The other personal characteristics are responsible, has an internal locus of control, morality, and altruism which are related to future orientation [4]. Water conservation is a significant aspect of sustainable behavior, and hence, it is important to instigate the characteristics to support the water saving program.

Another important aspect of a water conservation program is the use of language in the campaigns. Katz et al. [5] studied the comparative results of using two types of message, an assertive and a suggestive message phrasing in residential water conservation program among 1500 households. Assertive messages use a commanding tone, such as "You must conserve water," whereas suggestive messages employ a gentler language, such as "Please consider conserving water." The results show that the suggestive message language is more potential to accentuate change in residential water conservation behavior. Furthermore, Katz et al. [5] suggest that this might be due to the status of water as a basic needs resource, which may reduce the effectiveness of freedom-restricting language as implemented in an assertive tone. The relative success of the suggestive, or persuasive, message was also found by Landon et al. [6] representing the importance of language to achieve efficient households' residential water use.

Securing water supplies in urban areas poses challenges for policymakers and hence it is important to know the key determinants of household water use to design the appropriate water management campaigns. Fielding et al. [7] studied water use data from 1008 households in Queensland, Australia and found that demographic, psychosocial, behavioral, and infrastructure factors all play important roles in determining household water use. Household occupancy was found to be the most important predictor of water use; which is consistent with previous research. Households in drought regions and have higher-level water restrictions used less water than those who had less experience with drought. Culture also plays an important role; households who have a stronger culture of water conservation used less water. These findings highlight the importance of imposing policies that support longterm cultural shifts in the way people think about and use water.

\section{Methodology}

This study reports the examination of household water conservation program consists of focus group discussions (FGD) with villagers of Tianyar Village, Bali. This village is one of arid region in Bali, some areas experiencing severe drought without any support from the local water provider. Other areas enjoy the privilege of water supply from the local water provider as the locations can be reached by for such service. Residents in the latter areas are the main target of this program.

The water saving education program was attended by 50 participants three times FGD conducted in the village head office for three months. Together with the FGD, participants are also exposed to independent activities of household water saving which are:

1. Monitoring the use of water in the activity of washing eating utensils, vegetables and fruits and soaking frozen food by using less open tap water.

2. Wash clothes using water-saving materials, such as products that campaign for one-rinse.

3. Turn off the water tap while brushing teeth because it can save at least 40 liters of water.

4. Take a shower using a shower and turn it off when using soap.

5. Accommodate rainwater after the first day of the rainy season (to avoid pollution or pollution from the atmosphere). 
The activities are included in a checklist sheet that should be filled in by participants every day. The results of independent activities are reported and discussed among participants and mentors in the FGD to increase the awareness of the water saving.

\section{Results}

The number of participants attended the program are 50 villagers with the profiles as follows.

Table 1. Profile of participants.

\begin{tabular}{|l|c|c|c|}
\hline Gender & \multicolumn{2}{|c|}{ Female: $35 \%$} & Male: $65 \%$ \\
\hline Age & \multicolumn{2}{|c|}{$20-40$ years old: $50 \%$} & $41-60$ years old: $50 \%$ \\
\hline Occupation & Farmer: $62 \%$ & Employee/staff: & Unemployed (housewife): \\
& & $30 \%$ & $8 \%$ \\
\hline
\end{tabular}

The increasing awareness of the importance of water saving is indicated after three series of focus group discussions as follows.

\subsection{First focus group discussion}

First focus group discussion (FGD) was used as a beginning stimulation towards the water saving behavior. The idea of water saving is discussed and brainstormed among participants and with mentors during the session which last for one hour.

Around $62 \%$ of participants stated that currently, they do not experience the water scarcity, reflecting the main target of the program which comes from the areas supported by the local water provider. Almost all of the participants agree that it is their responsibility to do water saving, as can be seen from perceptions of several participants as follows.

"Yes, I agree because excessive water use can bring about drought. The example is the excessive use of artesian well which causes the water debit decreased so that the surrounding well will dry out." (Participant \#1)

“Agree, as water is the basic human needs." (Participant \#2)

"Agree, considering the increasing number of population which will increase the demand for clean water. Also, the price of water is still high, and sources of clean water are still scarce." (Participant \#3)

There was only one participant who stated that there is no need to save water, and even questioned: "Why should we save water?". Since the number of participants is only 50, the perception of this one villager might represent perceptions from other villagers who did not participate in the education program. The question came from a villager whose age is around 30 , works as an employee and live in the area enjoying water supply from the local water provider. This perception might reveal the lack of empathy toward the neighbors who cannot enjoy the privilege of water supply from the local water provider. Mentors of the education program decided to give stronger emphasis on the importance of water saving in the next focus group discussion by using a more assertive language to deliver the message. The session was ended with the distribution of the checklist sheet of water saving activities to be conducted independently by participants at home. 


\subsection{Second focus group discussion}

The second focus group discussion was held one month after the first one. The discussion was started by the reports of independent water saving activities conducted by villagers during the one-month period. The data can be seen in Table 2.

Table 2. Results of independent activities of water saving program.

\begin{tabular}{|l|c|}
\hline \multicolumn{1}{|c|}{ Activities } & Percentage \\
\hline Reducing bathing time & $50 \%$ \\
\hline Limit the amount of water used for bathing & $62 \%$ \\
\hline Turn off the faucet when brushing teeth & $73 \%$ \\
\hline Hold rainwater in a container & $73 \%$ \\
\hline $\begin{array}{l}\text { Limit the amount of water used for washing } \\
\text { clothes }\end{array}$ & $42 \%$ \\
\hline Use used bath water to water plants & $40 \%$ \\
\hline
\end{tabular}

The results from independent activities show an increasing awareness of the importance of water saving, including from the participant who was first reluctant to the program. All participants said that there are no obstacles for them to perform the activities; however, they demanded a program to save water in farming activities as majorities of the participants work as farmers. As a participant said:

"We can save water for ourselves; but how about our plants? If we limit the use of water, they surely will die, and we will have fail harvest." (Participant \#4)

This question might reflect the increasing awareness as there is a need to expand water saving beyond the household use. The demand was then accommodated in the third focus group discussion.

\subsection{Third focus group discussion}

The third focus group discussion is the last FGD in the water conservation program with an agricultural expert joins the discussion to provide information. In line with the demand from villagers, the expert explained the water conservation for the household plant as well as for farming.

The expert provides information on the plants that can treat detergent waste? The greywater treatment plant was introduced, where the treated water is used for hydroponics of food crops, which is quite normal to harvest several times. Several plants that can perform the function are Typha Angustifolia, water hyacinth, water jasmine, bamboo water, and star water. This is called a wetland or phytoremediation, as people can get benefit from the green plant, while the wastewater can be treated into proper irrigation water.

For farming, the technology of drip irrigation was introduced. In this technology, farmers are facilitated in overcoming the problem of providing water to their land with high efficiency. Irrigation water can be given directly to the root zone with no excessive volume. Drip irrigation is even claimed to be able to efficiently save more than 70 percent of water compared to channel irrigation. This technology consists of 2 models. The first model has a capacity of 2,200 liters with a 6-meter-high steel frame construction; while the second model has a simpler structure and consists of a 1,000-liter capacity water reservoir. The construction is also made of wood which is easily made or obtained around the land. 
Further discussions with villagers reflect their increasing knowledge of water saving in the household and for farming purposes, which generate positive feedbacks as perceived by several participants as follows.

"I am so grateful for joining this program as it does not only give me information on how to save water for my family daily lives but also on how to save water for my farm."

(Participant \#5)

"Even though I am not a farmer, but I love gardening. The information provided in this program is so useful for me as I can use the wastewater from bathing or washing activities for several plants. This gives my family double benefits."

(Participant \#6)

Overall, results of the series of FGDs show significant improvement in the residents' awareness towards water scarcity issue and empathy to other residents who experience the problem. The positive impacts were enabled through intensive discussions as part of the water saving campaign during the FGDs and the water saving activities that should be independently performed by participants at home. Other contributing factors to the success of the water conservation program come from the use of suggestive message as suggested by Katz et al. [5] and Landon [6] and the accommodation of participants' need to have information on water saving in the agricultural sector; which was accommodated in the third FGD. It is recommended that similar program in the future follow the same pattern to achieve the same success; and even beyond.

\section{Conclusions}

This study reported the household water conservation program for villagers of Tianyar, Bali who lives in arid regions. The regions consist of areas enjoying the water supply from local water provider, and some areas do not have such privilege. The educational program consists of several independent activities as well as a series of focus group discussions (FGD) to increase the community awareness on the methods to save water for household consumption.

The results indicate the rising awareness among villagers on the importance of water conservation which can be seen from the progress of the first FGD to the third. In the first FGD, there is one villager who was reluctant to do the water saving activities, which represent the lack of empathy toward the neighbors living in the areas without water supply from the local water provider. The reluctance was then reduced in the second and third FGD, presumably because of the assertive approach and useful information provided for villagers. At the end of the program, the water saving method for agriculture was also delivered which increase the benefits even more as the majority of participants work as farmers.

\section{References}

1. S. Olmstead, R. Stavins, Wtr. Rsc. Res. 45, 4 (2009)

2. H. Campbell, R. Johnson, E. Larson, Rev. of Plcy. Res. 21, 5 (2004)

3. V. Corral-Verdugo, B. Fraijo-Sing, J. Pinheiro, Int. Amr. J. Psy. 40, 2 (2006)

4. J. Allen, J. Ferrand, Env. and Bhv. 31, 3 (1999)

5. D. Katz, A. Kronrod, A. Grinstein, U. Nisan, Wtr. 10, 275 (2018)

6. A. Landon, A. R. Woodward, G. Kyle, R. Kaiser, J. of Cln Prd. 195, 56 (2018)

7. K. Fielding, S. Russell, A. Spinks, A. Mankad, Wtr. Rsc. Res. 48, 1 (2012) 